\title{
Evaluation of rumen transfaunation after treatment of rumen acidosis in cows
}

\author{
S.A. Galbat ${ }^{1}$ and H.G. Keshta ${ }^{2}$ \\ ${ }^{I}$ Department of Animal Medicine, Faculty of Veterinary Medicine, New Valley University, New \\ Valley, Egypt. \\ ${ }^{2}$ Department of Animal Medicine, Faculty of Veterinary Medicine, Matrouh University, Matrouh, \\ Egypt.
}

Received: 10 Sept. 2020 / Accepted 15 Nov. 2020 / Publication date: 20 Nov. 2020

\begin{abstract}
Many cows suffer from indigestion and rumen acidosis, in which rumen acidity drops to less than 5, and leads to the death of the ruminal protozoa in the rumen, a sharp decline in animal productivity, stoop rumination, eating and impaction with acidity of blood, exposing the animal to death and expose the owners to great losses, Solving the problem of indigestion by traditional methods leads to a prolonged suffering and absence of ruminal protozoa from the rumen, which prolongs the period of poor production and great money losses to the owners. But if the protozoa are transfaunated from a healthy, animal to the animals with acidosis, after treatment of the original cause and clinical signs it leads to a faster recovery, improved digestion, and a return to normal production. Accordingly, the idea of these experiment was based, which is transfaunation from healthy animals that were recently slaughtered in the abatouar to the rumen of four cows suffering from indigestion at a rate of 3 liters from ruminal fluid and the condition of the animals was followed after that, eating, digestion and general health condition in addition to following up the count of protozoa in the rumen ,Their multiplication and activity, as well as the productivity of the tranfaunated animals over the course of five weeks after recovery from acidosis, and the results were recorded consecutively, where there was a significant improvement in the condition of transfaunated animals and an increase in their productivity till reach to normal as Control group while that suffered from acidosis and treated by the traditional methods only without transfaunation take more time to back to normal in their milk production.
\end{abstract}

Keywords: indigestion, rumen acidosis, cow

\section{Introduction}

Clinical rumen acidosis remains the major cause of morbidity and mortality in modern ruminant production systems, acute rumen acidosis represents an economically important loss to the beef and milk production industry, Ruminants have a complex stomach system, in which the stomach is divided into four compartments, the rumen is the largest of which (Radostits et al., 2007)

The functional health of the reticle-rumen is an essential requirement for productive behavior, encompassing livestock health and animal welfare (Van Vuuren et al., 2012).

Under modern animal production systems, ruminants are fed high grain diets to maximize energy consumption and productivity (Oba and Wertz-Lutz, 2011).

Ruminants are adapted to digest and metabolis forage diets (Krause and Oetzel 2006).

Intensive fattening systems need rations containing high proportion of grains (sorghum, barley or corn), that when reach the rumen break down quickly producing large amounts of lactic acid that predispose to metabolic disorders (Smith, 1998).

Continuous anaerobic fermentation takes place by a complex community of microorganisms consisting of bacteria, protozoa. Fungi and may be other unknown microorganisms. When ruminants are born their rumen is in a germ-free condition and the unique flora and fauna start to be established after birth. (Williams and Coleman, 1997).

Clinical ruminal acidosis occurs when excessive levels of organic acids accumulate in the rumen, resulting in a rumen fluid $\mathrm{pH}$ of fall less than 5.2. (Owens et al., 1998; Nagaraja and Lechtenberg, 2007).

\section{Corresponding Author: S.A. Galbat, Department of Animal Medicine, Faculty of Veterinary Medicine, New} Valley University, New Valley, Egypt. Email: salahgalbat@yahoo.com 
Regardless of the initial cause, the pathogenesis of clinical rumen acidosis is the same. Ruminal bacteria that digest starches and sugars proliferate and increase their rate of carbohydrate fermentation. In the normal animal, or in animals with mild clinical disease, rumen buffering capacity and volatile fatty acid absorption match the rate of carbohydrate fermentation. In this scenario, the $\mathrm{pH}$ within the rumen will stay in a normal range between 5.6 and 6.9, with the higher $\mathrm{pH}$ range being more common in new world camelids (Owens et al., 1998; Nagaraja and itgemeyer, 2007; Smith, 1989).

Excessive feeding of rapidly fermentable carbohydrates commonly named as "grain overload," is the classic scenario leading to clinical rumen acidosis. , excess grain consumption is not essential to the development of the syndrome, because excess consumption of any rapidly fermentable carbohydrate (apples and other fruits, bakery waste products, incompletely fermented Brewery products, and standing green corn) is capable of providing the necessary substrate for the development of clinical disease (Radostits et al., 2007)

When production of volatile fatty acid and lactate exceeds the rate of absorption, rumen $\mathrm{pH}$ will begin to drop. volatile fatty acid and lactate increase in concentration within the rumen fluid and are absorbed into the systemic circulation (Johnson, 1991)

Although numerous microorganisms have been implicated in the development of disease, the primary bacterium thought to be associated with the progression of clinical signs is Streptococcus bovis. because of its rapid rate of division, ability to produce more ATP per unit time, and tolerance of a $\mathrm{pH}<5.5$, is the microorganism that sets the stage for acid production and make the symptom worst( Nagaraja and itgemeyer, 2007).

We are now trying to improve the rate of digestion of various feeds to generate conditions suitable for ruminants (Cheng et al., 1991).

The rumen microbiome is excessively complex, being include bacteria (up to $10^{11}$ cells $/ \mathrm{mL}$ ), protozoa $\left(10^{4}-10^{6}\right.$ cells $\left./ \mathrm{mL}\right)$, fungi $\left(10^{3}-10^{6}\right.$ zoospore $\left./ \mathrm{mL}\right)$, methanogens $\left(10^{6}\right.$ cells $\left./ \mathrm{mL}\right)$, and bacteriophages $\left(10^{7}-10^{10}\right.$ particles $/ \mathrm{mL}$ ) (Morgavi et al., 2013).

Microorganisms able to enzymatic detoxification. In the rumen by microbial enzymes (Kudo et al., 1986)

As there are too many toxic plants, especially in tropical countries, ruminal metabolism enzymatic detoxification (James et al., 1975 and Allison 1978).

The rumen microbes are considered as the most efficient microbial system digest lignocellulosic biomass (Flint et al., 2008)

The transfaunation procedure has also been recommended for cows with acidosis-related rumen stasis(Garry, 1990)

There is variability in the rumen microbial population between individual animals (Shabat et al., 2016).

From animals with a high feed intake suggesting a microbial may be responsible for more efficient digestion (Guan et al., 2008; Carberry et al., 2012)

Transfaunation is the process of transferring rumen fluid containing microbes and nutrients from healthy animals into animals with impaired rumen digestion. This method is believed to improve rumen function and has been used as an biotic treatment for ketosis, anorexia and several causes of indigestion such as rumen acidosis. That method recommended in numerous text books and practical guides to bovine medicine as mentioned in the review by Depeters and George (2014).

Exact role in ruminal fermentation and their contribution to the metabolism and nutrition of the hos tis still an area of questions (Williams and Coleman, 1997).

Rumen fermentation models offer the opportunity to study the rumen microbial population in the absence of host factors (Oss et al., 2016).

Defaunation is the removal of protozoa from the rumen and refaunation is the introduction of protozoa into the rumen. Scientific reports on the impact of presence or absence of rumen ciliates on ruminant performance have been falsifying each other; some researchers reported benefit effect of defaunation, while others disagreed with these results with or without bade effect on ruminal vital functions and animal health (Walker, 2000). 
Transfaunation or refaunation includes a broad spectrum of microorganisms including protozoa and bacteria that are transferred from rumen of a donor animal to the rumen of a recipient. Even though transfaunation has been an old practice for several years (Brag and Hansen, 1994). 2014)

A common medical practice in animal medicine to treat indigestion of ruminants (Smith,

There is still little scientific information regarding its benefits and mechanisms of actions (DePeters and George, 2014)

Rumen ciliates transfaunation and its effect on animal health and productivity especially milk fat $\%$ which is considered a measure of economics of milk and milk products (Mehta, 2014).

These symbionts have promoted with the host for millions of years under conditions of anaerobiosis, high dilution rates, high cell densities and protozoa predation (Selinger et al., 1996).

This selective pressure has accelerated the evolution of a microbioal toward a community that is highly specialized in digesting lignocellulosic. The host is dependent on many enzymes produced by the microbial community to convert complex fibrous substrates into volatile fatty acids and microbial protein that are utilized by the ruminant for maintenance, growth, and lactation (Selinger et al., 1996; Morgavi et al. , 2013).

Less than $50 \%$ of carbohydrates in low quality forages, such as straw, are digestible and useable by the host. Passage of lignocellulosic biomass from the rumen and restricted access of fibrolytic enzymes to targeted substrates are thought to limit the extent of plant cell wall digestion in the rumen (Weimer, 1996).

In Egypt, several authors; (Baraka, 2012; Saber, 2016; Saber et al., 2016; Al-Azazi et al., 2018) studied rumen ciliates of cattle, buffalos, sheep and camels from aspects of total protozoa count, morphology, proportions of ciliate families and ciliate culturing, and recommended future comprehensive studies to explain the benefits of transfer of cultivated ciliate cultures into defaunated or faunated animals on productive status of dairy and fattening ruminants. So, the aim of this study is to evaluate the benefits of transfaunation of mixed cultures of rumen ciliates on physical clinical examination, milk productivity.

\section{Material and methods}

\section{Animals}

12 milking cows with divided in to 3 groups lactating cows. The dairy cow were located in Elmenofia. The cows were housed in sheltered free stalls and had water was available ad libitum. Feed for each cow was purchased from the same source and fed to cattle in clean, sheltered mangers. Free-stall care, milking, mastitis control, and manure removal systems were similar.

1. 4 animal's transfaunated G1.

2. 4 animal's non-transfaunated G2.

3. 5 normal control group G3.

4.

\section{Procedures}

Cows with acidosis were treated medically

- Use sodium bicarbonate to reduce acidity in the rumen

- Fluid therapy.

- Anti-histaminic

- Anti-inflammatory

- Brood spectrum antibiotic

- Stomachic and laxatives

\section{Transfaunation procedure}

Two non-lactating ox served as rumen fluid (transfaunate) donors. To stabilize rumen conditions, donor cows were fed a mixed forage diet consisting of alfalfa and oat hay (50:50 ratio) for 3 weeks prior to the beginning of the study and daily thereafter until the last transfaunation procedure was performed. The transfaunated ( $3 \mathrm{~L})$ was collected from sieved rumen contents in the abattoir. 
Rumen fluid that filtered into the pipe through the perforations was evacuated via a stomach tube and was administered to cows assigned to the transfaunated group within 20 minutes of collection. Prior to the beginning of the study, but after equilibration to the forage diet

Cows assigned to the transfaunated group received $3 \mathrm{~L}$ of rumen fluid, and cows assigned to the control group received $3 \mathrm{~L}$ of tap water via a stomach tube on day 0 immediately after correction of rumen acidosis .

(Day 0). On days 0 (immediately after acidosis treatment) and 2, 5 cows each received $3 \mathrm{~L}$ of rumen fluid (transfaunated group) or $3 \mathrm{~L}$ of water (control group) via a stomach tube. Dietary drymatter intake and milk yield of each cow were recorded daily for 5 days, beginning immediately after acidosis treatment . rumen fluid samples were collected prior to acidosis and on days 2, 5, 15 and 35 after acidosis treatment .

4 Cows with acidosis were treated by transfaunation of 3 liters from healthy ox rumen fluid.

4 Cows with acidosis were treated by medical treatment only without transfaunation.

Control cows with received 3 liters of water.

Rumen protozoa were examined 2, 5, 15 and 35days after acidosis.

$\mathrm{PH}$ of rumen fluid was determined.

\section{Samples.}

1. Rumen samples.

2. Milk samples.

\section{Results}

All cows survived and completed their lactation.

1. Daily and cumulative feed intake and milk yield of cows in the transfaunated group were significantly greater than those of cows in the non-transfaunated group.

2. Cows in the transfaunated group had significantly normal total protozoal count and activity.

3. Cows in the non-transfaunated group had lower number of protozoal count and activity with low milk yield compared with control group and transfaunated .

Table 1: ruminal $\mathrm{PH}$

\begin{tabular}{cccc}
\hline Rumen PH & Group 1 transfaunated & Group 2 non-transfaunated & Group 3 control \\
\hline Day 1 & $6.6 \pm 0.2$ & $5.6 \pm 0.1$ & $6.8 \pm 0.5$ \\
Day 3 & $6.7 \pm 0.4$ & $5.9 \pm 0.3$ & $6.8 \pm 0.3$ \\
Day 15 & $6.8 \pm 0.5$ & $5.8 \pm 0.5$ & $6.8 \pm 0.2$ \\
Day 35 & $6.8 \pm 0.8$ & $6.6 \pm 0.4$ & $6.8 \pm 0.4$ \\
\hline
\end{tabular}

Table 2: Protozoal crudeness and viable cell \% in ruminal samples

\begin{tabular}{|c|c|c|c|}
\hline $\begin{array}{c}\text { Total protozoal } \\
\text { count }\end{array}$ & Group 1 transfaunated & $\begin{array}{ll}\text { Group } \quad 2 & \text { non- } \\
\text { transfaunated }\end{array}$ & Group 3 control \\
\hline Day 2 & with $40 \%$ viable cell & with $10-20 \%$ viable cell & $\begin{array}{l}\text { Over crowded with } 90- \\
100 \% \text { viable cell }\end{array}$ \\
\hline Day 5 & $\begin{array}{l}\text { less crowded with } 40-50 \\
\% \text { viable cell }\end{array}$ & with $20-40 \%$ viable cell & $\begin{array}{l}\text { Over crowded with } 90- \\
100 \% \text { viable cell }\end{array}$ \\
\hline Day 15 & $\begin{array}{l}\text { crowded with } 80-90 \% \\
\text { viable cell }\end{array}$ & with $40 \%$ viable cell & $\begin{array}{l}\text { Over crowded with } 90- \\
100 \% \text { viable cell }\end{array}$ \\
\hline Day 35 & $\begin{array}{l}\text { Over crowded with } 90- \\
100 \% \text { viable cell }\end{array}$ & with $50 \%$ viable cell & $\begin{array}{l}\text { Over crowded with } 90- \\
100 \% \text { viable cell }\end{array}$ \\
\hline
\end{tabular}

Table 3: Milk yield during 5 weeks

\begin{tabular}{cccc}
\hline Milk yield. & Group 1 transfaunated & Group 2 non-transfaunated & Group 3 control \\
\hline Day 2 & $2.7 \pm 3.2$ & $1.2 \pm 0.0$ & $8.6 \pm 3.6$ \\
Day 5 & $5.2 \pm 2.3$ & $2.7 \pm 0.4$ & $8.4 \pm 2.5$ \\
Day 15 & $8.2 \pm 4.9$ & $3.5 \pm 1.5$ & $8.6 \pm 1.0$ \\
Day 35 & $8.6 \pm 2.7$ & $6.7 \pm 4.5$ & $8.5 \pm 2.2$ \\
\hline
\end{tabular}


Table 4: Protozoal activity in ruminal samples

\begin{tabular}{cccc}
\hline Protozoal Motility & Group 1 transfaunated & Group 2 non-transfaunated & Group 3 control \\
\hline Day 2 & + & + & +++++ \\
Day 5 & ++ & + & +++++ \\
Day 15 & +++ & + & +++++ \\
Day 35 & +++++ & ++ & +++++ \\
\hline
\end{tabular}

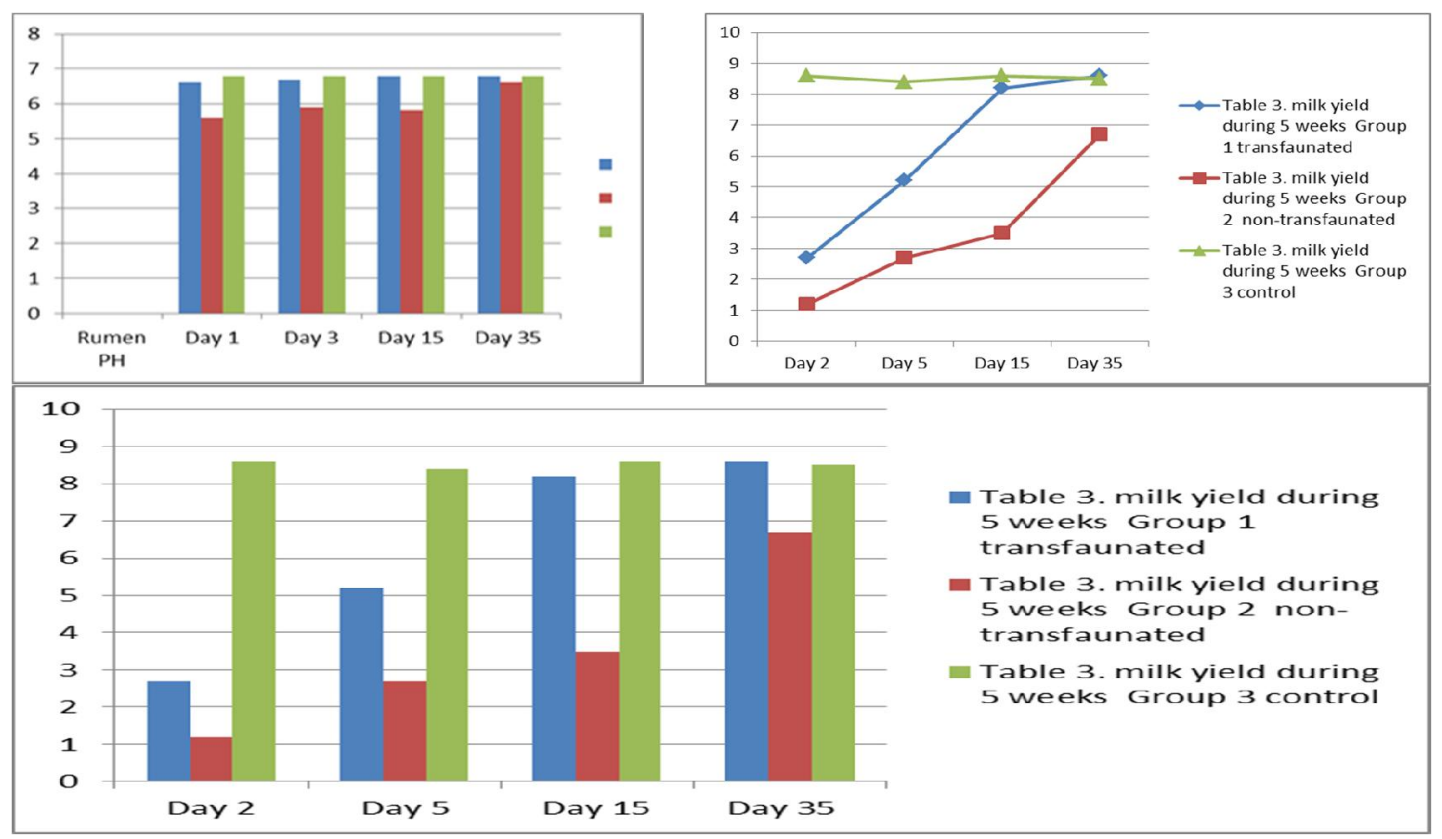

Fig. 1: Rumen $\mathrm{pH}$ and animal productivity.

Eight cows suffered from acidosis came to a private clinic in al- menofia governorate. The cows were treated by medication till the signs of indigestion disappeared and the clinical symptoms back to normal healthy state. Except low milk yield still low for a time may be expanded to several weeks. 4cows were transfaunated by 3liters of ruminal fluids (filtrated from ruminal contents of freshly slaughtered ox) the other 4 cow not receive transfaunation after recovery from acidosis and 4 as control) originated from same environment, Beginning on day 2 recovery from acidosis until day35, cows in the transfaunated group had significantly greater daily feed consumption than cows in the non-transfaunated group, The cumulative 5-day milk yields of cows in the transfaunated and control groups were significantly greater than non transfaunated group. Transfaunated cows had significantly greater daily milk yield than non-transfaunated cows on days 2, 5, 15, and 35 (Table 3 ).

Rumen protozoa activity and motility are significantly improved in the transfaunated group than non-transfaunated group.

The $\mathrm{pH}$ values of rumen fluid samples were no significant differences in the $\mathrm{pH}$ of rumen fluid between control and transfaunated cows at any time but the PH. is more suitable to rumen digestion in the two groups than non-transfaunated group along the period of experiments.

\section{Discussion}

Administration of rumen fluid to cows convalescing after acidosis correction had beneficial effects.

Cows that received rumen fluid had significantly greater feed intakes, significantly greater daily milk yields, significantly lower the acidity in rumen fluid, the feed intakes of transfaunated and control cows were more than non transfaunated group; appetite differences could have contributed to the variability of rumen protozoa, $\mathrm{pH}$ values. Because rumen fluid $\mathrm{pH}$ may remain low for as long as several weeks in non transfaunated animals exposed to indigestion after feeding concentrate, 
Rumen transfaunation has a long history, being considered a valuable treatment for poor thrift calves and for cows suffering from indigestion .controlled, experimental studies to support the recommendations. We believe that Rager and others (2004) the main improvements were observed in the parameters of number of protozoa, percentage of vital protozoa,

The increase in the number and the percentage of viable protozoa also allows conclusions about bacterial and biochemical activity in the rumen, which is more difficult to examine under field conditions (Holtenius, Björck and Hoflund, 1959).

The medication may have influenced rumen microbiota and rumen fermentation (Fiore, Morgante, (Muraro, Boso, and Gianesella, 2016).

Aside from the improvement of the quality of rumen fluid, feed intake also significantly increased after transfaunation as described by Rager et al. (2004)

The main result of this study is that transfaunation volumes, $3 \mathrm{~L}$, had positive effects on relatively inactive rumen fluid and surprisingly significant improvement of the animal productivity.

3 liter rumen fluid is easily and within 2 min obtainable using stomach Tubes fitted with suction pumps, without considerable defense reactions of donor cows (Steiner et al., 2015). No rumen cannulated cows are necessary., the sampling of small volumes such as $3 \mathrm{~L}$ is very unlikely to cause any negative effects on the health of the donor. Healthy donors from the same farm, in the same state of lactation and fed the same ration as the patient should be selected. Using animals from the same farm reduces the risk for transmission of infectious agents, which should be taken into biosecurity consideration. In conclusion, transfaunation of small volumes of rumen fluid proved to be very efficient at improving rumen function and feed intake. It should be used more widely as a valuable practical supportive treatment accelerating recovery after surgical correction or medical treatment, and as a simple therapy for indigestion. It is inexpensive, fast and does not result in withdrawal periods.

\section{Conclusions}

Indigestion, Impaction and ruminal acidosis are a metabolic disorder of ruminants fed a high grain rations, with deficient in fiber, it can also occur because of sudden change in ration or errors in nutritional management. It can be prevented by the inclusion in the diet of buffer substances, feed additives, antioxidants and essential oils. The change of forage to concentrate in the diet should be carried out gradually. Animal health and production is improved, by preventing ruminal acidosis. Benefits of rumen transfaunation for cows after acidosis correction is increase in milk yield and digestibility of dry matter in compared with non-transfaunated cows.

\section{References}

Al-Azazi, A.S., F. Tayeb and T. Baraka, 2018. Effect of herbal mixture on selected rumen and serum constituents in sheep. Biosci Res., 15: 1653-1660.

Allison M.J., 1978. The role of ruminal microbes in the metabolism of toxic constituents in : Effects of poisonous plants on livestock. Edited by Keeler, R F., Van Kampen, K. R. and James, R. f Academic Press. USA, 101-116.

Baraka, T.A., 2012. Comparative studies of rumen $\mathrm{pH}$, total protozoa count, generic and species composition of ciliates in camel, buffalo, cattle, sheep and goat in Egypt. J Am Sci, 8: 448-462.

Brag, S. and H. Hansen, 1994. Treatment of ruminal indigestion according to popular belief in Sweden. Revue Scientifique et Technique de l'Office International des Epizooties, 13: 529-536.

Carberry, C.A., D.A. Kenny, S. Han, M.S. Mccabe, and S.M. Waters, 2012. Effect of phenotypic residual feed intake and dietary forage content on the rumen microbial community of beef cattle. Appl. Environ. Microbiol., 78, 4949-4958. doi: 10.1128/aem.07759-11

Cheng, K.-J., C.W. Forsberg, H. Minato and J.W. Costerton. 1991. Microbial ecology and physiology of feed degradation within the rumen. In: Physiological Aspects of Digestion and Metabolism in Ruminants (Ed. T. Tsuda, Y. Sasaki and R. Kawashima). Academic Press, New York, 595-624.

Depeters, E. and L. George, 2014. Rumen transfaunation. Immunol Letters, 162: 69-76. 
Fiore, E., M. Morgante, M. Muraro, M. Boso, and M. Gianesella, 2016. Methaphylactic effect of tulathromycin treatment on rumen fluid parameters in feedlot beef cattle. Canadian Journal of Veterinary Research, 80: 60-65.

Flint, H.J., E.A. Bayer, M.T. Rincon, R. Lamed, and B.A. White, 2008. Polysaccharide utilization by gut bacteria: Potential for new insights from genomic analysis. Nat. Rev. Microbiol., 6:121131. doi:10.1038/nrmicro1817.

Garry, F., 1990. Indigestion in ruminants. In: Smith BP, ed. Large animal internal medicine. St Louis: Mosby Year Book Co., 747-782.

Guan, L.L., J.D. Nkrumah, J.A. Basarab, and S.S. Moore, 2008. Linkage of microbial ecology to phenotype: Correlation of rumen microbial ecology to cattle's feed efficiency. FEMS Microbiol. Lett. 288:85-91. . doi:10.1111/j.1574- 6968.2008.01343.x.

Holtenius, P., G. Björck, and S. Hoflund, 1959. Die untersuchung von pansensaftproben. Deutsche Tierarztliche Wochenschrift, 66: 554- 558.

James, L.F., M.J. Allison, and E.T. Littledike, 1975. Production and modification of toxic substances in the rumen. In : Digestion and metabolism in the ruminants. Edited by : McDonald, I. W. and Warner, A. C. T. Univ. New England Publ. Unit., Armidale, Anstrai., 577-590.

Johnson B., 1991.Nutritional and dietary interrelationships with diseases of feedlot cattle. Vet Clin North Am Food Anim Pract; 7:133-42.

Krause, K., and G. Oetzel 2006. Understanding and preventing subacute ruminal acidosis in dairy herds: A review. Anim Feed Sci Tech., 126: 215-236.

Kudo, H., K.J. Cheng, W. Majak, J.W. Hall and J.W. C,isterton, 1986. In vitro degradation of mimosine by microorganisms from the esophageal sac of voles (Microtus arvalis). Canadian Journal of Animal Science, 66: 517-551.

Mehta, B.M., 2014. Chemical composition of milk and milk products, in: Handbook of food chemistry. Springer, 1-34.

Morgavi, D.P., W.J. Kelly, and P.H. Janssen et al., 2013. Rumen microbial (meta) genomics and its application to ruminant production. Animal, 7:184-201

Nagaraja, T.G., and K.F. Lechtenberg, 2007. Acidosis in feedlot cattle. Vet Clin North Am Food Anim Pract; 23:333-50.

Nagaraja, T.G., and E.C. Titgemeyer, 2007. Ruminal acidosis in beef cattle: the current microbiological and nutritional outlook. J Dairy Sci., 90 (Suppl 1):E17-38.

Oba, M., and A. Wertz-Lutz 2011. Ruminant nutrition symposium: Acidosis, new insights into the persistent problem, J. Anim., Sci., 89: 1090-1091.

Oss, D.B., G.O. Ribeiro, M.I. Marcondes, W. Yang, K.A. Beauchemin, R.J. Forster, et al., 2016. Synergism of cattle and bison inoculum on ruminal fermentation and select bacterial communities in an artificial rumen (rusitec) fed a barley straw based diet. Front. Microbiol., 7:2032. doi: 10.3389/fmicb.2016.02032

Owens, F.N., D.S. Secrist, W.J. Hill, et al., 1998. Acidosis in cattle: a review. J. Anim. Sci; 76:27586.

Radostits, O.M., C.C. Gay, K. Hinchcliff, and P.D. Constable, 2007. Veterinary Medicine. A Textbook of the Diseases of Cattle, Horses, Sheep, Pigs, and Goats, 10th edn. Saunders Elsevier, Philadelphia,

Rager, K.D., L.W. George, J.K. House, and E.J. Depeters, 2004. Evaluation of rumen transfaunation after surgical correction of left-sided displacement of the abomasum in cows. Journal of the American Veterinary Medical Association, 225: 915-920. https://doi. org/10.2460 /javma. 2004.225.915

Saber, M., 2016. Effect of Field and Experimentally-induced Cases of Frothy Bloat on Physical Examination, Rumen Fermentation Pattern and Blood Constituents in Baladi Egyptian Sheep. Int J Livest Res., 6: 46-63

Saber, M., T. Baraka and F. Tayeb, 2016. Seasonal rumen fermentation pattern of Egyptian sheep in health and field digestive disorders. Vet. Med. J., 62: 31-43.

Selinger, L.B., C.W. Fosberg, and K.-J. Cheng, 1996. The rumen: A unique source of enzymes for enhancing livestock production. Anaerobe 2:263-284. doi:10.1006/anae.1996.0036. 
Shabat, S.K.B., G. Sasson, A. Doron-Faigenboim, T. Durman, S. Yaacoby, and M.E. Berg Miller, et al. , 2016. Specific microbiome-dependent mechanisms underlie the energy harvest efficiency of ruminants. ISME J., 10: 2958-2972.

Smith, B.P., 2014. Large animal internal medicine. 4th Ed. Elsevier Health Sciences.

Smith, J.A., 1989. Noninfectious diseases, metabolic diseases, toxicities, and neoplastic diseases of South American camelids. Vet. Clin. North Am. Food Anim. Pract., 5:101-43.

Smith, R., 1998. Impact of diseases on feedlot performance: A review. J. Anim. Sci. 76: 272-274.

Steiner, S., A. Neidl, N. Linhart, A. Tichy, J. Gasteiner, K. Gallob, and T. Wittek, 2015. Randomised prospective study compares efficacy of five different stomach tubes for rumen fluid sampling in dairy cows. Veterinary Record, 176: 50- 55.

Van Vuuren, A.D., S. Calsamiglia, and P. Uden, 2012. Rumen health: A $360^{\circ}$ analysis. Anim. Feed Sci. Tech., 172: 1-3.

Walker, N.D., 2000. Nutrient requirements and metabolism of rumen microorganisms, 62-75, retrived from http://www.dairyweb.ca/Resources/CANC2008/Walker.pdf

Weimer, P.J., 1996. Why don't ruminal bacteria digest cellulose faster? J. Dairy Sci. 79:1496-1502. doi:10.3168/jds.S0022-0302 (96)76509-8.

Williams, A. and G. Coleman, 1997. The rumen protozoa, in: The rumen microbial ecosystem. Springer, 73-139. 